\title{
LA ORGANIZACIÓN DE LA ADMINISTRACIÓN PÚBLICA EN UNA ESCALA LOCAL: LA PROVINCIA DE COQUIMBO, CHILE, EN LA DÉCADA DE 1820*
}

\author{
Elvira López TaVerne \\ Pontificia Universidad Católica de Chile \\ elviraelopez@gmail.com
}

\section{RESUMEN}

Este artículo busca reflexionar en torno al proceso de formación estatal en Chile desde una escala local, la provincia de Coquimbo. El análisis se centra en la organización institucional y la conformación de la administración pública, pues creemos que ambos fenómenos son un ámbito privilegiado para estudiar las tensiones, los desafíos, las contradicciones y los obstáculos que comportó dicho proceso en sus primeros años. En específico, se abordan las siguientes preguntas: cómo se forma la administración pública en una escala provincial: ¿cuáles son los desafíos que enfrenta el gobierno a la hora de implementar esta administración en la provincia de Coquimbo?, ¿cuáles son sus principales características en los años posteriores a la independencia?, y por último, ¿qué nos dicen estas sobre el proceso de formación estatal?

Palabras clave: Construcción estatal, Administración pública, Historia administrativa, Chile, Siglo XIX.

* Este artículo forma parte de la investigación postdoctoral Fondecyt 3160051, "El Estado en la provincia. La organización institucional y la formación de la burocracia en Coquimbo, 1810-1860". 


\title{
THE ORGANIZATION OF PUBLIC ADMINISTRATION AT LOCAL LEVEL: THE PROVINCE OF COQUIMBO, CHILE, IN THE 1820s
}

\begin{abstract}
The aim of this article is to reflect on the process of State-building in Chile at a local level, in the province of Coquimbo. The analysis has been centered on the institutional organization and forming of public administration, because we think that these phenomena are an ideal area to study the tensions, challenges, contradictions and obstacles that took place during the first years of that process. Specifically, the following questions are addressed: how is public administration conformed at a provincial level; which are the challenges faced by the government to implement this administration in the province of Coquimbo? which are its main characteristics in the years after independence? And lastly, what do they tell us about the process of State-building?
\end{abstract}

Keywords: State-building, Public administration, Administrative history, Chile, $19^{\text {th }}$ century. 


\section{INTRODUCCIÓN}

Este artículo busca reflexionar en torno al proceso de formación estatal en Chile desde una escala local, la provincia de Coquimbo. El análisis se centra en la organización institucional y la conformación de la administración pública, pues creemos que ambos fenómenos son un ámbito privilegiado para estudiar las tensiones, los desafíos, las contradicciones y los obstáculos que comportó dicho proceso en sus primeros años. Sobre el Estado se ha escrito mucho, y a pasar de la diversidad de posturas, muchos autores coinciden en señalar el carácter dominante de la presencia estatal en el proceso de formación de la nación (Góngora 1981, Eyzaguirre 1967, Jocelyn-Holt 1992), y en el peso que tuvo la institucionalidad en la construcción de la sociedad chilena (Salazar y Pinto 1999). Ahora bien, la reflexión sobre el Estado ha privilegiado una envergadura nacional, e incluso los estudios sobre el rol de la ciudadanía y la sociedad civil en la construcción del mismo han optado por esta escala (Pinto y Valdivia 2009, Pinto 2011) ${ }^{1}$. Por ello, el estudio de la organización de la administración pública y lo que este análisis nos pueda enseñar sobre la formación estatal desde una escala local resulta interesante y novedoso.

La elección de la provincia de Coquimbo responde a un criterio preciso $^{2}$. Desde los tiempos de la conquista ella constituyó, junto a la de Concepción y de Santiago, uno de los tres polos de desarrollo económico, social y político en los que se dividió históricamente el territorio chileno (Carmagnani 1973, Hurtado 1966, Cavieres 1993). Así, constituye un terreno privilegiado para estudiar cómo se organiza y reestructura la administración en torno a la nueva realidad política y económica que se instaura tras la independencia, principalmente en razón de su vocación económica: la minería (Domeyko 1876, Aracena 1884, Carmagnani $1963)^{3}$.

1 La excepción serían los estudios sobre comunidades marginadas al proceso de construcción estatal, como las indígenas. Véase Pinto Rodríguez (2003).

2 En la época estudiada la provincia de Coquimbo limita al norte con el desierto de Atacama, en el paralelo 23, y al sur con el río Choapa. Sus principales centros urbanos son Copiapó y La Serena, y los puertos de Huasco, Caldera y Coquimbo. Según el censo de 1843 su población asciende a 103.748 habitantes, lo que ese año representa un 9,7\% de la población nacional. Véase Pérez Rosales (1859).

3 Cabe recordar que el modelo económico de la nueva república se construye en torno al desarrollo del comercio internacional. El ingreso público proviene de los impuestos a las importaciones y la balanza se equilibra con la exportación de metales (Cavieres 1998, Ortega 2005, Salazar 2009). El mineral de cobre encabeza esta lista y los 
Teniendo en cuenta estos antecedentes buscamos responder a las siguientes preguntas: ¿cómo se forma la administración pública en una escala provincial?, ¿cuáles son los desafíos que enfrenta el gobierno a la hora de implementar esta administración en la provincia de Coquimbo?, ¿cuáles son sus principales características en los años posteriores a la independencia?; y por último, ¿qué nos dicen estas sobre el proceso de formación estatal?

Las comunicaciones entre las autoridades gubernamentales y el material generado por la incipiente burocracia repiten los mismos tópicos a lo largo de la década de 1820: la omnipresencia de la guerra y la precariedad de la administración. Ambos tópicos constituyen nuestros ejes temáticos.

El fenómeno de la guerra trasciende el ámbito puramente administrativo, puesto que determina aspectos de la economía, la demografía y la vida social de la época; y como se verá, establecer un espacio civil donde se desarrolle la burocracia es un desafío mayor.

La segunda característica es la precariedad de la administración provincial. Como lo muestran los documentos -no podemos hablar de estadística-, los funcionarios son escasos, muchos se desempeñan ad honorem, circulan entre las distintas instituciones y están insertos en redes sociales y familiares. Destaca así el carácter patrimonial y los vínculos sociales que existen al interior de la administración, lo que nos habla de "estados porosos" (Pro 2013: 10), sensibles a las lógicas sociales y culturales de la época. Desde esta perspectiva, las relaciones clientelares y de redes generan vínculos de lealtad igualmente poderosos que aquellos que responden a las jerarquías verticales de la administración pública, es parte de la cultura política de la época, y de otro modo no se entienden muchas de las prácticas de los gobernantes y funcionarios (Imízcoz 1998, Gribaudi 2009, Pietschmann 1998). En las primeras décadas del siglo XIX los límites entre la esfera pública y privada son borrosos; este es un legado importante del pasado colonial y no se revierte de un día para otro. En esta línea, es un error considerar los rasgos patrimoniales en la administración solo como un aspecto nocivo, pues caemos en la teleológica visión weberiana, que supone el triunfo-evolución de la burocracia moderna por sobre la administración patrimonial y los liderazgos carismáticos. Al contrario, la persistencia de rasgos patrimoniales puede promover efectividad, lealtad, disciplina y eficiencia administrativa (Rudolph y Hoeber 1984: 122).

Respecto a los años estudiados, la década de 1820 es un período convulso. El aprendizaje político (Heise 1978) se da en el marco de la presencia

yacimientos se ubican mayoritariamente en Coquimbo. 
constante de la guerra, que a su vez conlleva una crisis económica y productiva mayor (Salazar 2009). La relación entre las provincias históricas de Coquimbo, Santiago y Concepción vive también momentos álgidos, no hay acuerdos preexistentes sobre el modelo político-administrativo ha implementar tras la independencia, y es sobre la marcha que estos se van ensayando y poniendo en práctica (Cartes 2014). Este "desorden" político se refleja a nivel administrativo y en la documentación, y revela lo aleatorio e incierto del proyecto de construcción estatal.

Finalmente, la situación en estos años es compleja por ser un momento de transición. La guerra implica transformaciones en el ámbito político y en algunas estructuras administrativas e institucionales, pero otros aspectos perduran, como la legislación y parte del reglamento administrativo que rige a los funcionarios.

\section{EL DESAFÍO DE FORMAR UN ESPACIO CIVIL EN LA ADMINISTRACIÓN}

La creación de una administración civil es un proceso lento y complejo, y representa un desafío para el nuevo gobierno. Cabe recordar que el proceso de construcción estatal tiene su origen y está inmerso en las guerras de independencia; la guerra es un fenómeno omnipresente en estos años.

Por otra parte, los líderes políticos que encabezaron dicho movimiento provenían en su mayoría del mundo militar, y su liderazgo y legitimidad venía de allí, de las batallas en las que participaron y del rol que desempeñaron en la guerra. Baste citar a quienes estuvieron a la cabeza del gobierno desde la independencia para constatar la predominancia que tuvieron en política (Bernardo O’Higgins, 1817-1823; Ramón Freire, 1823-1826; Manuel Blanco Encalada, 1826; Francisco Antono Pinto 1827-1829; José Joaquín Prieto, 1831-1841; Manuel Bulnes, 1841-1851) todos militares de alta graduación). Es por ello, entre otras razones, que una vez finalizada la guerra no se cuestionó su participación en la dirección del nuevo gobierno (Ossa 2014).

Si nos remontamos en el tiempo, en Chile la tradición militar tiene un peso simbólico y práctico histórico. Dada su situación de frontera y de guerra "permanente", el gobierno de la Capitanía General se confió a militares de carrera, la economía local se estructuró en torno al real situado proveniente de Lima, y la construcción del imaginario aristocrático de la elite tuvo como elemento central la tradición militar; es decir, esta configuró la sociedad, la economía, la política y la cultura local (Góngora 1981). 
Si se considera este aspecto, el problema de asentar la legitimidad de las autoridades civiles sin recurrir a escalafones o cargos militares comporta un gran desafío. Los debates y conflictos en torno a las jurisdicciones y a la procedencia del poder no son temas nimios, pues cuestionan los orígenes del poder y la autoridad de los funcionarios, la jurisdicción, de dónde procede o emana la autoridad y en nombre de quién actúan los administradores; temas complejos que nos permiten pensar y cuestionar los cimientos del proceso de formación estatal.

El año 1818 el Director Supremo Bernardo O’Higgins se encuentra en campaña en el sur, y el gobierno delegado dispone "declarar que los Gobernadores Intendentes tuviesen el grado de Coroneles de Ejército por el tiempo de su gobierno" (Letelier 1886: 80). A su retorno el Director solicita al Senado derogar dicha orden, pues:

En el dia conviene economizar los grados militares... para lo sucesivo, ningun empleo civil debe tener distintivo militar, temporal ni perpétuo, a ménos que recaiga en persona que lo sea de profesion, pues a los militares no debe obstar el servicio en los empleos civiles i políticos para el goce de su grado i fuero, ni para los ascensos a que sean acreedores segun sus méritos [...] (Letelier 1886: 80).

La intención del Senado era dotar de estatus militar a las autoridades civiles, buscando ajustar el escalafón castrense con el de la administración interior del gobierno. El hecho de que el grado se identificara al cargo y no a quien lo detentara es significativo. La respuesta de O'Higgins puede leerse como una defensa del estatus militar, pero también busca establecer una separación entre el mundo civil y el militar, que en efecto se rigen por códigos y reglamentos distintos. No obstante, el hecho de que se mantenga abierta la posibilidad de que un militar sea nombrado para un cargo civil muestra que es el cargo civil el que debe legitimarse. Para zanjar la discusión, el Senado acuerda que en el caso de que los gobernadores de provincia sean militares, "lo sirva cada uno con el grado que tenga", y si recae en "paisanos", sea sin distintivo militar, "ni temporal ni perpetuo" ${ }^{4}$

La dificultad de separar los ámbitos civil y militar reaparece con el tema de los nombramientos. En octubre de 1818, el Director Supremo manifiesta sus resquemores frente a un artículo de la Constitución que sanciona la forma de designar a los empleados subalternos. El artículo estipulaba que los nombramientos debían hacerse a consulta de los jefes respectivos y publicarse con ocho días de anterioridad. El Director estima que "el artículo

4 Con este decreto se derogan los anteriores (Letelier 1886). 
enunciado es en parte inverificable respecto del ramo militar", puesto que va contras las lógicas internas de cómo opera el mundo castrense (Letelier 1886: 35). Por su parte, el Senado también se cuestiona si se debe aplicar esta disposición a los empleos militares (Letelier 1886: 33).

Las observaciones del Ejecutivo y del Senado muestran que no es posible aplicar un mismo código legal al mundo castrense y a la administración civil. Es cierto que los militares son también empleados del gobierno y desempeñan labores de funcionarios, pero con características particulares propias al cuerpo castrense.

La cercanía de la guerra tampoco facilita este proceso de diferenciación. En febrero de 1818, nueve meses antes de la situación ya descrita y ante la inminencia de un ataque enemigo, O'Higgins dicta un decreto llamando al servicio militar a todos los empleados públicos. Se incluye a los abogados, relatores, procuradores, escribanos de Gobierno, del Cabildo, de la Cámara de Justicia, los receptores y los empleados de todas las oficinas de Hacienda, Consulado y Minería, a excepción de los empleados de las Secretarías de Estado, Tesorería de Hacienda y administración de Correos, quienes deberían presentar una papeleta otorgada por sus superiores. El empleado que desobedeciere perdería en el acto su empleo (Chile 1898: 248).

Lo interesante es que se exceptúa del servicio a ciertos funcionarios, aquellos indispensables para que funcione el engranaje del gobierno. Por otra parte, la participación de los empleados públicos en un batallón al mando de un oficial del Ejército implica una sumisión al estatus militar, a sus lógicas y códigos. Esto se refleja en la transformación del lenguaje observada en el decreto, que pasa de mencionar como "empleados públicos" a quienes luego son "los nuevos militares" (Chile 1898: 248).

Los vínculos y la relación compleja que existe entre el espacio civil y militar se observan también en las denominaciones que tienen las nuevas autoridades. En la Constitución de 1818, el jefe del poder Ejecutivo, el Director Supremo del Estado, tendrá tratamiento de "Excelencia" y sus honores serán los de Capitán General del Ejército "conforme a las ordenanzas militares" (Chile 1818: IV). Por su parte, el gobierno de las provincias estará a cargo de los gobernadores-intendentes, quienes a su vez serán secundados de tenientes-gobernadores. Si bien esto no resulta novedoso, pues es sabido que los escalafones de la administración civil tomaron su modelo de la jerarquía militar, dada la historia particular del territorio chileno, la desvinculación de los militares del gobierno será un proceso muy lento, si es que podemos decir que en algún minuto esto se 
logró plenamente -vista la injerencia que el mundo castrense tiene hasta el presente en la vida pública nacional-.

La documentación muestra que durante los primeros ańos de formación del Estado, el gobierno y lo que podríamos considerar su administración civil, se encuentran dominados por el influjo que ejercen los militares. Además de controlar la cabeza del Ejecutivo y el poder Legislativo (de forma indirecta, pues los senadores son nombrados por O,Higgins), el Director Supremo nombrará a militares y soldados en distintos puestos y niveles de la administración pública. Estos nombramientos obedecen a distintas razones: buscan premiar méritos y lealtades, son una solución para desmovilizar las tropas, y también un instrumento para afianzarse en el poder. La práctica de los nombramientos directos por designación del jefe de Gobierno busca suplir los vacíos que dejó la guerra, producto de la huída o destitución de muchos españoles peninsulares; sin embargo, incide directamente en un fuerte control de la administración (López Taverne 2014: 251).

El proceso de organización de una administración o burocracia ${ }^{5}$ implica la creación de un espacio de poder civil al interior del gobierno, la injerencia del mundo castrense viene entonces a complicar las cosas. Mencionamos que el poder simbólico de los líderes independientes proviene de su participación en la guerra de independencia, son los héroes, y por ello no se cuestiona que tomen las riendas en la dirección del gobierno. Sin embargo, cuando se busca asentar la legitimidad de una burocracia civil, el nombramiento de militares es un problema, dada su doble vinculación como funcionario -en relación a la proveniencia de su legitimidad, y a las lealtades y jerarquías a que obedece-. La provincia de Coquimbo es un caso ilustrativo en este aspecto.

5 Utilizamos indistintamente estos términos, entendiendo que en este período la burocracia escaparía a las características y modelos teóricos que la definen. 


\section{Mapa 1: Provincia de Coquimbo, 1826}

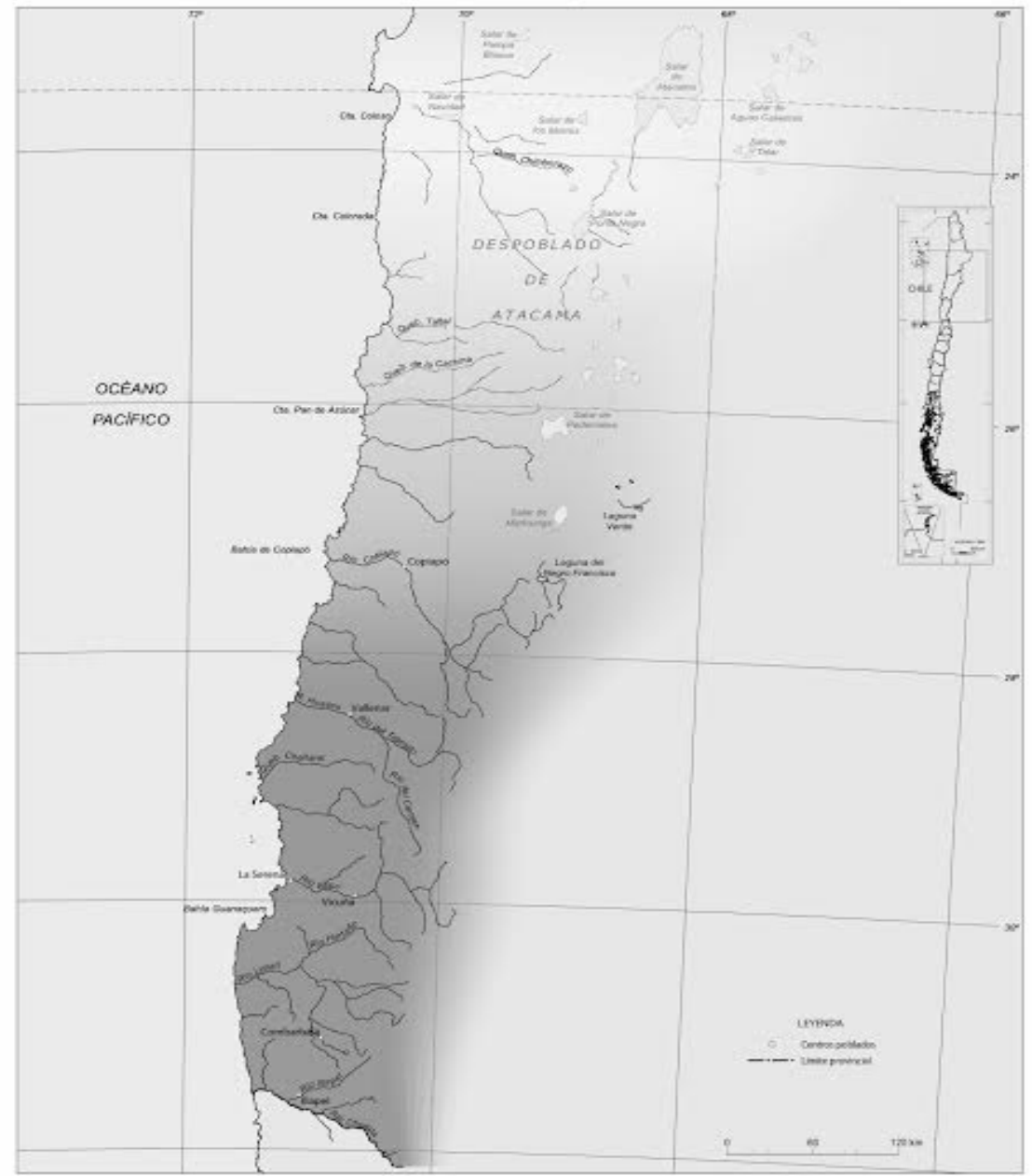

Fuente. Sagredo, González y Compan (2016).

En su calidad de región minera, el aporte de la provincia a la economía del país era imprescindible ${ }^{6}$, al tiempo que el puerto de Coquimbo era un

6 En palabras del intendente Francisco Antonio Pinto, "La explotación de las minas es un ramo de industria de los de primera importancia en esta Provincia. Siendo toda ella una coagulación de metales de Oro, Plata, Cinabrio, Cobre, etc. no es fácil calcular la opulencia y abundancia que derramará en todos sus habitantes el laborío de estas". "Mensaje con que el Gobernador de la Provincia de Coquimbo Don Francisco Antonio Pinto abrió las sesiones de la Asamblea instalada en la Capital de aquella provincia el 26 del pasado junio [de 1825]", en ANIC. vol. 17, fojas 486-490. 
enclave estratégico en la ruta hacia el Perú. Así, en la década de 1820 el gobierno de la provincia fue ejercido por militares de destacada trayectoria en las campañas de la independencia: Luis de la Cruz (Concepción 1768, Santiago 1828), José Joaquín Vicuña (1786, La Serena 1857), Francisco Antonio Pinto (Santiago 1785, Santiago 1858) y José María Benavente (Concepción 1785, La Serena 1833).

En 1817, cuando los patriotas asumen la dirección del gobierno, se nombra a los administradores de las provincias, poniendo en esos cargos a individuos de confianza ${ }^{7}$. El informe al Gobernador Intendente de la provincia señala:

Exmo. señor. Las virtudes civicas del actual Gobernador de Coquimbo me hacen creer que su desprendimiento le persuadirá que no habiendo sido un militar, es imposible que no se vea en conflictos para dirigir la fuerza de un punto tan interesante. Tampoco habria como arguirle de responsabilidad en un caso de compromiso despues de ser autorizado sobre la inteligencia de no haber profesado esta carrera. Si la necesidad de consiliar el respeto al rango de su empleo le adquirió el grado de Coronel de Milicias, sus atribuciones no pueden salir de una esfera que aventure la seguridad de la Provincia, cuyo regimen dignamente desempeña (ANIC, vol. 3, sin foja, Santiago, 17 de octubre de 1817, firma el general José de San Martín).

En esta comunicación también se le comunica que será el coronel don Luis de la Cruz quien asumirá el cargo, "y él, y su cuerpo no seria regular dependiesen de un Gefe sin inteligencia anticipada de la disciplina militar. Un fisico jamas resolveria Theologia” (ANIC, vol. 3, sin foja, Santiago, 17 de octubre de 1817, firma el general José de San Martín). Por estos motivos se declara que los intendentes que no sean veteranos ejerzan solo

Véase Pinto y Ortega (1990).

7 En la provincia de Coquimbo la transición al gobierno independiente se dio de manera bastante pacífica. El gobernador realista, teniente coronel Manuel Santa María, ante a la incapacidad de hacer frente a las fuerzas patriotas que al mando del comandante Juan Manuel Cabot estaban encargadas de liberar a la provincia, emprendió la retirada hacia la capital. Muchos funcionarios públicos y algunos comerciantes peninsulares le siguieron. Ante el vacío institucional y de gobierno, los vecinos de La Serena nombraron por Gobernador a Manuel Antonio Irribarren, capitán de artillería y favorable a la causa patriota. Una vez en el gobierno, Bernardo O’Higgins nombró una comisión compuesta por Joaquín Vicuña, José Antonio Ovalle y Martín Larraín a fin de organizar el gobierno de los pueblos y distritos del norte. Véase Diego Barros Arana (1889: 564-568). 
el gobierno político, quedando la Comandancia de Armas a cargo del veterano de más alta graduación.

Estas medidas afectan a toda la jerarquía administrativa provincial. Es el caso del partido de Huasco, a cargo del Teniente Gobernador Francisco Sains de la Peña, capitán del Ejército. A fines de 1818, ante su renuncia, el gobierno reconoce su honor y acierto, "habiendo llenado las esperanzas que obligaron a su nombramiento", y se le concede el uso de uniforme de capitán del Ejército (AMI., vol. 46, sin foja, 3 de noviembre de 1818). Este nombramiento "obligado" de individuos de confianza es la tónica de los primeros ańos luego de la independencia. Es lo que sucede en la villa de San Ambrosio de Vallenar, vecina de Huasco, donde el primer Teniente Gobernador "independiente", fue elegido por su vecindario, aunque mediado "[...] por incinuacion del señor comandante de vanguardia despues de un serio examen sobre las virtudes y patriotismo de los ciudadanos de esta jurisdicción [...]" (ANIC, vol. 7, foja 817). En el partido de Illapel se nombra como delegado al Teniente Coronel del Ejército, Enrique Lasalle (ANIC, vol. 13, Santiago, 21 de octubre de 1824, sin foja, firma Francisco Antonio Pinto) y unos años más tarde encontramos como delegado de San Isidro de Vicuña (Elqui) al coronel Santiago Iglesias (ANIC, vol. 14, San Isidro de Vicuña, sin foja).

La injerencia del mundo militar se manifiesta hasta las jerarquías más bajas del gobierno local. En mayo de 1822 se sanciona un decreto supremo en materia de secretarías y asesorías de las intendencias, donde se estipula que las secretarías de las intendencias se servirán por oficiales del Ejército ${ }^{8}$. Esta medida puede leerse como un intento de establecer jerarquías similares entre la burocracia civil y el mundo castrense, de abrir un nuevo campo a veteranos, o también como una instancia de control sobre el desarrollo de la administración civil.

Dos años antes, en respuesta a una comunicación del Intendente de Coquimbo sobre las funciones de los asesores letrados, el gobierno había decretado que: "Los asesores de las intendencias, son tenientes letrados con jurisdicción contenciosa civil y criminal en sus respectivos territorios,

8 Este decreto también estipula que la Intendencia de Santiago y la de Concepción tendrán tres oficiales. Las demás Intendencias y Gobierno de Valparaíso tendrán dos oficiales. ANIC, vol. 17, foja 359. Con anterioridad a este decreto ya se desempeñaban en estos puestos algunos militares, como en la Intendencia de Coquimbo, donde en enero de 1820 había sido nombrado el capitán Esteban Sáez como Secretario. ANIC, vol. 13, Santiago, 8 de enero de 1820, firma Joaquín Echeverría. 
supliendo las veces del jefe de la Intendencia en su falta, enfermedades y ausencias [...]"(AMI, vol. 46, foja 131). Se seńalaba que el Teniente letrado asumiría las labores del Intendente en todos los negocios de la Intendencia y de la Superintendencia de Hacienda, excepto en lo referente al mando militar, que quedaría a cargo del oficial de mayor graduación. Se observa entonces, nuevamente, la necesidad de otorgar un grado militar a los funcionarios civiles, en este caso de "tenientes".

Las disputas en torno al gobierno civil y militar de la provincia vuelven a surgir cada cierto tiempo. En junio de 1829, el Gobernador de Copiapó recurre al Intendente de la provincia para quejarse del comandante de armas de ese partido. En su respuesta, la autoridad provincial estipula de forma clara las jerarquías:

La Comandancia de Armas de un partido nunca ha supuesto independencia del Gobierno. El Gobernador es siempre un subinspector de ellas, es decir: superior del mismo Comandante. Este es solo un titulo honorifico, y por cuyo conducto debe el Gobernador disponer de las milicias, como en esta Capital hay Intendente y Comandante de Armas, y todo lo que dispone el primero lo hace por conducto del segundo que deve obedecerle; lo mismo es en Santiago, donde el Presidente de la República es el Jefe Supremo del Exercito, pero quando dispone lo manda por conducto del Comandante de las Armas, y este lo hace saber a los oficiales y tropa subalterna (ANIC, vol. 25, sin foja, La Serena $1^{\circ}$ de junio de 1819).

Se precisa que la comandancia de don Ramón Goyenechea (Comandante de Armas de Copiapó) afecta únicamente a las milicias de ese partido, pero siempre bajo las órdenes del gobierno. El Intendente afirma que lo contrario sería "un fenómeno en la politica", pues el gobierno sería "el juguete de la Comandancia, o mejor decir un Subalterno", para terminar afirmando que la Comandancia es un brazo auxiliar del Gobierno.

La tensión que implica la creación de un espacio civil en la administración gubernamental se manifiesta también al interior de las mismas instituciones. Las oficinas de Aduana, por ejemplo, son un escenario constante de conflictos en torno a la delimitación de las funciones.

Las características de muchas oficinas de Aduana, y en particular los resguardos cordilleranos, hacen de estos espacios un lugar en el que las funciones de policía y vigilancia -respecto al tránsito o depósito de mercancías- se asemejen a las de un establecimiento militar, los límites son difusos. Todas las aduanas cuentan con un resguardo, que compuesto 
por un militar y un grupo de soldados, tiene por misión la custodia de las mercaderías que circulan o se almacenan allí, y por sobre todo, el deber de vigilar y evitar el contrabando. Según la locación, el Resguardo cuenta también con guardas de a caballo, marineros y botes. Pese a su carácter militar, esta institución depende del Departamento de Hacienda, quien cubre su presupuesto?.

Los conflictos que se viven entre los comandantes de resguardo y los administradores de Aduana ejemplifican la confrontación constante entre la esfera civil y la militar. Estos resultan embarazosos ya que cada parte acude a su autoridad jerárquica, que a su vez busca influir en el Ministro de Hacienda. Este Secretario debe dirimir por una de las partes, buscando siempre mantener el equilibrio, puesto que una oficina de Aduana sin resguardo resulta impensable.

En 1818 el contador mayor Rafael Correa de Saa expone bien el criterio que justifica la separación entre ambas instituciones (Resguardo y Aduana de Coquimbo):

[...] ¿que no sabe el administrador el enlace que entre si tienen las funciones de la comandancia con las de aquella Aduana para el caval desempaño de ambos cargos? ¿que no conoce que la seguridad de los intereses publicos ha exigido tomar medidas entre la Aduana y Comandancia de modo que reciprocamente se impidan los abusos de uno y otro ministerio llegando al extremo de hacer independiente las comandancias de las aduanas generales, a fin de que la dependencia no pueda ocasionar condecendencias perjudiciales a los intereses del Estado? [...] (AMI, vol. 9, 3 de agosto de 1818, foja 248).

Elcaso ilustralas dificultades queimplicala creación de una administración civil en el marco de la formación estatal. La superposición de jerarquías y la delimitación imprecisa de las funciones son justamente impedimentos al buen funcionamiento de la incipiente burocracia. Las instituciones de Hacienda $-\mathrm{y}$ en particular las aduanas-, son espacios privilegiados para ver cómo se desarrolla un proceso de burocratización, entendido como el proceso de jerarquización y reglamentación del cuerpo de empleados que sirven al Estado (O’Donnell 2004). La dualidad civil-militar y la circulación de dinero (entre otras características), atraen desde temprano la atención

9 El personal de los resguardos representa un porcentaje significativo de los empleados de Hacienda, lo que repercute en un presupuesto a su vez elevado. En 1824, por ejemplo, el presupuesto de aduanas y resguardos representa el 44,9\% del total asignado al ramo de Hacienda, véase (Ministerio de Hacienda 1824). 
de las autoridades, que buscarán reglamentar, jerarquizar, ordenar; en fin, burocratizar estos espacios claves de la administración.

En las finanzas provinciales se refleja también la centralidad que tiene la guerra y lo militar en estos ańos. Como muestra el estado de cuentas de la Administración de Rentas Unidas y depositaria de secuestros de Coquimbo, para el período que va de la entrada del Ejército Restaurador hasta el 31 de marzo de 1817, los ramos de entrada fueron los siguientes:

\section{Tabla 1: Entradas de la administración de Rentas Unidas y Secuestros Coquimbo}

\begin{tabular}{cc} 
Ítem & Monto \\
\hline Caudales secuestrados por pertenencias de prófugos & $11.563,4$ \\
Ídem. del Bergantín apresado la Rosita & $2.453,2$ \\
Ídem de José Antonio Picon & 402,6 \\
La Renta de Tabacos del prófugo administrador Navas & 214 \\
La renta de tabacos consumos & 4.320 \\
Pólvora & 114,6 \\
Papel sellado & 82,5 \\
Barajas & 20,3 \\
Aduana del prófugo administrador Lujan & 3.947 \\
Ídem por derechos del viento & 60,1 \\
Ventas de efectos secuestrados & $1.699,5$ \\
Total & $24.878,4$ \\
Fuente: AMH, Vol. 3, Coquimbo 10 $^{\circ}$ de abril de 1817, sin foja.
\end{tabular}

Las cifras de la Tabla 1 muestran el peso que tienen las confiscaciones y secuestros en los ingresos fiscales, un $64,8 \%$ del total corresponde a estos ítems mientras que los ingresos tradicionales alcanzan solamente un $35,2 \%$.

Lo interesante es señalar que los datos de la provincia de Coquimbo son un reflejo de lo que ocurre a escala nacional (López Taverne 2011).

El año 1817 los ramos extraordinarios (secuestros, dineros tomados al enemigo, empréstitos forzosos, donativos voluntarios, presas y comisos, entre otros) corresponden al 59, 7\% de las entradas del fisco a nivel nacional (aduanas 13,4\% y ramos ordinarios 26,9\%) (Dirección General de Contabilidad 1901). 


\section{Tabla 2: Gastos de la administración de Rentas Unidas y Secuestros Coquimbo}

\begin{tabular}{|c|c|}
\hline Ítem & Monto \\
\hline Entregados para pago de sueldos de la tropa & 6.603 \\
\hline Ídem al proveedor general de la tropa & 602,7 \\
\hline Ídem para gratificación a la tropa y servicios hechos a la Patria & 306 \\
\hline Ídem por arrendamientos de pastos para las cabalgadas de la tropa & 31 \\
\hline $\begin{array}{l}\text { Gastos de la expedición al puertos para impedir el desembarco de } \\
\text { los enemigos }\end{array}$ & 551,4 \\
\hline Ídem de efectos comprados para pertrechos de guerra & 134,6 \\
\hline $\begin{array}{c}\text { Ídem de descarga y fletes de los efectos de los bergantines } \\
\text { apresados Rosita y Concordia }\end{array}$ & 229,6 \\
\hline $\begin{array}{l}\text { Ídem de los fletes y mozos pagados para el transporte y arreglo de } \\
\text { los efectos secuestrados y otros gastos }\end{array}$ & 62 \\
\hline Ídem del tribunal de secuestros & 50 \\
\hline Premios y más gastos pagados por tabacos & 279,7 \\
\hline Abonos de entregas hechas por tabacos & 627,7 \\
\hline Sueldos de la Aduana & 322,5 \\
\hline Gastos & 9.801 \\
\hline Existencia en cajas & 15.077 \\
\hline $\begin{array}{c}\text { Total } \\
\text { Fuente. } A M H \text { Vol } 3 \text { Conuimho } 10 \text { de ahri }\end{array}$ & $\begin{array}{r}24.878 \\
817 \sin \end{array}$ \\
\hline
\end{tabular}

La Tabla 2 revela que nueve de los once ítems de gasto corresponden a gastos asociados a la guerra, un $87,4 \%$ del gasto total, mientras que solo un 3,3\% está destinado a la administración (en este caso a los sueldos del personal de aduanas). Estas cifras no dejan lugar a dudas sobre el objetivo primordial de los primeros meses de gobierno: ganar la guerra y afianzarse en el poder, aunque también indican que la administración era muy pequeña y únicamente vinculada al Departamento de Hacienda.

Respecto del gasto, la realidad provincial se condice asimismo con la escala nacional, donde la preeminencia de la inversión en la guerra resulta indiscutible; un 92,7\% de la inversión total en el año 1819 (no se cuentan con presupuestos detallados para años anteriores).

Las tablas anteriores ilustran que la injerencia de la guerra trasciende el ámbito puramente administrativo. El posicionamiento de los militares en los puestos claves del gobierno de la provincia es parte de un fenómeno mayor; la precaria economía provincial también se organizará en torno al fenómeno de la guerra. 


\section{ORGANIZANDO LA ADMINISTRACIÓN LOCAL: LA PROVINCIA DE COQUIMBO EN LA DÉCADA DE 1820}

Tras derrocar al gobierno realista, luego de la Batalla de Chacabuco en febrero de 1817, el primer objetivo de los líderes patriotas es afianzarse en el poder. El contexto político es delicado, las campañas contra el Ejército Real prosiguen en la zona centro sur, y en la misma capital y el territorio "liberado" no todos son adictos a la causa independiente. Por otro lado, las premuras económicas son grandes y sostener al Ejército se ha vuelto una tarea difícil. Ambas situaciones, una de carácter político y la otra económico, son las que determinan las primeras medidas administrativas respecto a la provincia de Coquimbo: establecer el orden, extraer recursos, confiscar las propiedades de los enemigos y aportar con hombres, alimentos y animales de transporte a la tropa.

Estas medidas de orden económico y político-administrativo nos permiten abordar una característica central de la administración local en esta década: la precariedad ${ }^{10}$. Este rasgo puede parecer evidente y propio de un Estado en formación, de esta entelequia (Godoy 2016); no obstante, consideramos que analizar en detalle este aspecto da luces sobre el mismo proceso de construcción estatal.

\section{MEDIDAS DE ORDEN ECONÓMICO}

Respecto a las propiedades de los enemigos, a comienzos de abril de 1817 el Intendente señala al Director Supremo que se ha publicado y hecho circular el bando relativo al decomiso de las propiedades "de individuos residentes en dominios Españoles, asi continentales como ultramarinos" (AMH, vol. 3, La Serena, 6 de abril de 1817, foja 27, firma Manuel Antonio de Iribarren ).

La urgencia no es menor, pues como informa la misma autoridad, en la fuga hacia la capital que emprendieron "los enemigos de la causa que alimentava este Pueblo", se contaban el administrador de tabacos Vicente de la Nava (europeo), el "desnaturalizado americano" Antonio de Azagra, y el procurador y síndico de la ciudad José Barra (catalán). El embarazo es que "los dos primeros llevaron consigo todo el caudal de sus oficinas" (AMH, vol. 3, La Serena, 6 de abril de 1817, foja 60, firma Manuel Antonio de Iribarren), el dinero de donativos (a la causa patriota), de la Administración

10 En sus dos acepciones: de poca estabilidad o duración; que no posee los medios o recursos suficientes, Diccionario de la Lengua Española, Real Academia de la Lengua Española. 
de Tabacos y la Caja de Hacienda (AMH, vol. 3, Coquimbo, 5 de marzo de 1817, foja 68, firma Manuel Antonio de Iribarren). Por esta razón señala que:

No he podido indagar las cantidades que existian de cuenta de los ramos que administraban, por no haver dejado los documentos y libros respectivos a sus destinos, y el ultimo cargo tambien con el Libro padrón de ciudad; de modo que por esta falta no puede hacerse cobro alguno ni suplirse el perjuicio que reciven los propios de este pueblo (AMH, vol. 3, La Serena abril 6 de 1817, foja 60, firma Manuel Antonio de Iribarren).

La cita evidencia que las dificultades enfrentadas la nueva administración no son menores. La situación de guerra y la necesidad de financiarla motivan la instauración de donativos, empréstitos forzosos, confiscaciones, y toda una variedad de disposiciones para aumentar el escuálido erario fiscal.

El Intendente solicita recurrentemente a los tenientes gobernadores que colaboren en esta causa. Al Teniente Gobernador del partido de Huasco, por ejemplo, se pide "... que a la mayor prontitud remita a consignación de V.S. los caudales del Estado para que de alli se trasladen a esta Tesoreria General prefiriendo su remesa en libranzas del mejor abono" (ANIC vol. 3, Santiago, 28 de mayo de 1817, sin foja, firma Miguel Zañartu), lo que se encarga también al Intendente, en el caso de que reciba estos caudales en efectivo. El Teniente de San Rafael de Rosas, por su parte, comunica el estado de la Administración de Tabacos y los caudales que encontró en las arcas, aunque se excusa de que la contribución asignada a los españoles será infructuosa porque éstos son pocos y están en una situación crítica. Sí puede aportar con caballos pertenecientes al Estado, a los que tiene en recuperación en la cordillera y que promete remitir al cuartel de Los Andes cuanto antes (AMH, vol. 3, San Rafael de Rosas, 15 abril de 1817, foja 74, firma José del Solar). Desde Copiapó a su vez, en el extremo norte de la provincia, el teniente Miguel Gallo envía el estado de las rentas y de la administración de las propiedades secuestradas, del rateo, de las existencias en dinero y especies de la renta de tabacos, y de la contribución extraordinaria impuesta a los europeos de ese partido (AMH, vol. 3, fojas $76,115$ y 119$)$.

Si bien la mayor parte de los archivos revela la situación calamitosa del erario público, tanto en la capital como en las provincias, y las autoridades locales reiteran constantemente las dificultades para cumplir con el rateo y contribuciones que tocan a su partido, en ciertos momentos predomina el entusiasmo. En mayo de 1817 el bergantín Salvaje se encuentra en la 
bahía de Coquimbo con armas a la venta y el Intendente decide levantar una subscripción voluntaria para comprar doscientos sables y la cantidad de fusiles que permitan los fondos. Con este motivo incita el ánimo de los vecinos, por medio de una proclama, y no duda "corresponda en todo el partido a la cantidad que deseo, pues el entusiasmo de estos havitantes es en el grado de no reservar recurso alguno que contribuya a su defenza y seguridad" (AMH, vol. 3, La Serena, 29 de mayo de 1817, foja 155, firma Mariano Peñafiel).

Pero no todas las autoridades locales están en situación de responder a las expectativas del gobierno. Es el caso del Teniente Gobernador de Illapel, contra quien se levantan quejas "por su desidia en los deberes públicos", a saber, que "Hasta ahora está por cumplir la remesa de cobres que prometio para municiones, y que son ya muy urgentes". La solución es simple, se le depone y nombra un funcionario interino de la satisfacción del Intendente, mientras que a Guzmán (el antiguo Teniente Gobernador), se le conmina a reincorporarse al Ejército y ponerse a disposición del general en jefe (ANIC vol. 3, 27 de diciembre de 1817, sin foja, firma Miguel Zañartu).

\section{MEDIDAS DE ORDEN POLÍTICO-ADMINISTRATIVO}

La purga de funcionarios realistas es otro de los objetivos apremiantes, como le informa al Intendente de Coquimbo el Ministro de Interior: "[...] averiguará V.S. si entre los jueces subalternos y del campo hay algunos que no sean desididos patriotas, y en caso de haberlos lo avisara proponiendo otros que tengan esta calidad y demas necesaria para que los subroguen [...]" (ANIC vol. 3, Santiago, julio 2 de 1817, sin foja, firma Miguel Zañartu). El administrador de Rentas Unidas de la villa de San Rafael de Rosas (Illapel), Ramón Undurraga, se ve en esta situación, el Teniente Gobernador lo separa de su cargo pues en su calidad de Español y no de Patriota "no obstante que me parece no será perjudicial existiendo en esta como un simple vecino [...] me ha compelido a separarle de dichos empleos" (AMH, vol. 3, San Rafael de Rosas, 29 de marzo de 1817, foja 19, firma Diego Guzmán Ibáńez), nombrando interinamente a Pedro del Castillo, "decidido patriota". Se siguen así las directrices emanadas desde el gobierno central, que cinco días después de la batalla de Chacabuco había emitido un decreto en el que se acordaba,

[...] que a ningún individuo del Reino que no sea adicto al sistema de la patria y lo manifieste sin equivocación, se confiera empleo alguno civil o militar con declaración que debe ser despojado del que actualmente sirva el antipatriota o de ideas contrarias; y si estas influyen contra la tranquilidad y seguridad pública, justificando que 
sea el crimen en la forma ordinaria, sufrirá el condigno castigo que corresponda (Chile 1898: 197).

A fin de depurar la provincia de enemigos, se encarga al Intendente la creación de un Tribunal de seguridad, "compuesto de tres vocales patriotas de los mas honrados, y comprometidos con la causa de America”, y cuyo objeto principal será "separar a los enemigos encubiertos de la causa que se hallan diseminados por la campaña" y que causan "perjuicios incalculables" a la causa, en especial algunos religiosos cuyo influjo "es sumamente pernicioso". De forma paralela se establece una Junta de Arbitrios para cooperar y apoyar al Intendente en toda clase de materias "que sirvan al sosten de los Pueblos y del Estado en la presente guerra" (ANIC vol. 3, 21 de enero de 1818, sin foja, firma Miguel Zañartu).

Las medidas que toma el gobierno para afianzarse en el poder y establecer el orden son numerosas; sin embargo, las autoridades locales se enfrentan con un problema mayor: la capacidad de ejecutar los designios del gobierno, conflicto inherente a los primeros momentos del proceso de construcción estatal. La capacidad de ejercer la fuerza, la coacción, es un elemento consustancial a un Estado propiamente constituido.

El caso de Illapel (el partido más al sur de la provincia de Coquimbo) es demostrativo. En comunicación al Intendente de Coquimbo, el Teniente Gobernador de ese partido señala que le es "moralmente imposible" verificar la recluta que se le ordena practicar en su partido, pues estas reclutas "no pueden hacerse sin valerme de la fuerza, atendiendo a que este es un Pueblo sin opinion" (ANIC, vol. 6, San Rafael de Rosas Illapel, 5 de noviembre de 1817, firma Diego Guzman e Ivañez), eufemismo para expresar que no es adicto a la causa patriota. "Para hacerlas de este modo de este modo caresco de fuerza, y el emprehenderla sin ella es exponerme a que quede burlado un proiecto tan interesante al Estado [...]" (ANIC, vol. 6, San Rafael de Rosas Illapel, 5 de noviembre de 1817, firma Diego Guzman e Ivańez). Por esto pide al gobierno dos banderas, un cabo, cuatro soldados y al menos cien fusiles, para formar una compañía cívica "que sirva de seguridad a las reclutas que se vayan acopiando". Sin embargo, y visto que no ha recibido la contestación que el gobierno le prometió en un correo pasado, se dirige al Intendente para que le auxilie en esta solicitud. Finaliza su carta señalando que crear esta compañía no es únicamente necesario para la defensa, "sino tambien para contribuir al entusiasmo e ideas que es presiso influir en todas estas gentes a favor de la Independencia" (ANIC, vol. 6, San Rafael de Rosas, Illapel, 5 de noviembre de 1817, firma Diego 
Guzman e Ivañez) $)^{11}$.

La capacidad de coacción es indispensable en instituciones como los resguardos, encargados de controlar el comercio y disuadir el contrabando. Es por ello que en 1830 el visitador fiscal Victorino Garrido comprueba con espanto las "nuevas faltas y viejos abusos" cometidos en la administración de las rentas fiscales, llegando al extremo de que el Resguardo de la Aduana de Coquimbo "no tiene un bote, faluas ni embarcación de ninguna clase", con la que "pasar las visitas y ejercer los demas actos que le competen" (AMH, vol. 74, La Serena, 22 de julio de 1830 sin foja, firma Victorino Garrido). Señala además que la capitanía del puerto se haya en el mismo estado, no teniendo quien la sirva. La indignación del visitador se comprende, aunque también revela el estado de precariedad de las instituciones fiscales provinciales que en ocasiones era desconocido por las autoridades centrales; en el fondo se revela que esta institución estatal, al igual que muchas otras, no cuenta con la capacidad de ejercer sus funciones.

Lo que está en juego en una de las atribuciones intrínsecas del Estado, cuyas instituciones supuestamente cuentan con los recursos para efectivizar las decisiones que toman (O'Donnell 2011: 2); Estado que por otra parte, y siguiendo la definición más clásica de Weber, cuenta con la supremacía en el control de los medios de coerción física en el territorio que reivindica como soberano.

\section{LA PRECARIEDAD DE UNA ADMINISTRACIÓN EN FORMACIÓN}

Resulta complejo establecer una estadística de la burocracia provincial en estos años. La década de 1820 es un período de fuertes transformaciones, reina un desorden que se refleja a nivel administrativo y en la documentación. Será recién a mediados de siglo que se crea la Oficina Central de Estadística (1843), que busca, justamente, obtener una rigurosidad mayor en la recolección y observación de los datos. El desarreglo que se observa en los archivos revela lo aleatorio e incierto del proyecto de construcción estatal; las autoridades locales hacían camino al andar.

Los presupuestos no detallan el número de funcionarios, y es a través de los decretos de nombramientos, renuncias, y otro tipo de documentos

11 Esta "desafección” a la causa se mantiene. En 1824 el futuro Intendente José María Benavente, en su tránsito hacia Coquimbo, destaca el número de españoles avecindados en ese partido, que los habitantes son inquietos y "no muy adictos al sistema”, y que no hay sujetos que puedan desempeńar el cargo de Delegado. ANIC, vol. 17, La Serena, 28 de Julio de 1824, foja 410, firma José María Benavente. 
que se puede reconfigurar el entramado de la burocracia local. De acuerdo a las fuentes, los ámbitos en que se desempeńan los empleados son: administración, Hacienda y Justicia.

A mediados de la década de 1820 la estructura burocrática se organiza del siguiente modo: a la cabeza de la provincia figura el Gobernador Intendente, secundado por los tenientes gobernadores de Copiapó, Vallenar, Elqui, Combarbalá, Illapel. En la capital provincial la secretaría cuenta con dos oficiales y en el resto de gobernaciones generalmente con un Secretario u Oficial (que en ocasiones es el mismo Escribano del Cabildo) ${ }^{12}$.

En lo que respecta a Hacienda, tras la independencia la administración de alcabalas de la provincia accede al rango de Aduana General.

\section{Tabla 3: Empleados de la Aduana General de Coquimbo en 1825}

\begin{tabular}{ccc} 
Nombre & Clase & Dotación \\
\hline Custodio Amenábar & Ministro Tesorero & 1500 \\
Antonio Cordobés & Ministro Contador & 1500 \\
José Vicente Castellón & Vista y Primer Oficial & 800 \\
José Gregorio Meri & $2^{\circ}$ Oficial & 500 \\
Eulogio Castro & $3^{\circ}$ Oficial & 300 \\
Rafael Morgado & $4^{\circ}$ Oficial & 300 \\
Lorenzo Veliz & Portero & 100 \\
Fuente: AMH, Vol. 46, Coquimbo 19 de enero de 1825, sin foja.
\end{tabular}

Las aduanas de Copiapó y Huasco cuentan a su vez con un Ministro de Aduana y un oficial (pueden ser dos). Por otra parte hay un Administrador de Alcabalas con subalternos en las villas principales y gobernaciones. Las aduanas tienen un Aduana, compuesto por un Comandante de Resguardo y un grupo de soldados o guardas. En el caso de Coquimbo, este cuenta con un Comandante, un cabo, nueve guardas y dos guarda botes $(\mathrm{AMH}$, vol. 46, Coquimbo, 19 de enero de 1825, sin foja).

Se debe señalar que en los primeros años las aduanas y tesorerías formaban una misma institución, que se encargaba de controlar y regular el comercio exterior e interior y de cobrar los impuestos. Con el tiempo estas dos funciones se separarán; por un lado se tiende disminuir las numerosas partidas que constituían pequeñas entradas para el fisco, y se privilegia

12 Véase, por ejemplo, el caso de Vallenar en ANIC vol. 7, Vallenar, 20 de octubre de 1817 , sin foja. 
aquellas rentas más significativas ${ }^{13}$; y por otra, la irrupción de los impuestos al comercio exterior y su creciente peso en la estructura del ingreso fiscal supone una transformación primordial frente al comportamiento de las rentas coloniales. Como resultado las aduanas cobrarán un creciente protagonismo.

En el ámbito de la justicia, la provincia cuenta con un juez de letras. La administración judicial, de acuerdo a su Reglamento de 1824, reconocía como funcionarios subalternos a los inspectores de distritos, subdelegados y alcaldes de primer voto en las villas cabeceras (Bilot 2012, Enríquez 2016). Esta convivencia entre el esquema de administración de justicia de la época colonial y los primeros decenios republicanos, tiene como consecuencia numerosas querellas en torno a la jurisdicción y atribuciones de las autoridades para levantar causas, llevar procesos e impartir justicia; los límites son imprecisos y el peso de la tradición jurídica colonial choca en ocasiones con las atribuciones que las autoridades estatales buscan reafirmar ${ }^{14}$.

Como se señaló en los párrafos precedentes, la estadística sobre los funcionarios es difusa. A ello contribuye el hecho de que no siempre son nombrados por las autoridades centrales del poder ejecutivo, sino por las autoridades locales, los intendentes, los gobernadores, las asambleas provinciales y el Cabildo ${ }^{15}$. En la visita fiscal que realiza Victorino Garrido

13 La estructura de los impuestos no varió mucho tras la independencia. Hasta la década de 1850 las rentas se siguen clasificando en contribuciones directas, indirectas, monopolios y rentas eventuales. Las entradas directas comprenden aquellas que afectan a la propiedad y las personas, e incluyen la contribución territorial, el catastro, el derecho sobre imposición de capitales, patentes, y peajes. Las rentas indirectas incluyen por su parte los derechos de aduana (importación y exportación), y los derechos de almacenaje, faro, muelle, tonelada y remolque. Los monopolios comprenden las especies estancadas, tabaco, naipes y papel sellado. Finalmente, los ramos eventuales corresponden a las rentas provenientes de la venta de terrenos fiscales. Véase Oficina de Estadísticas (1961: 119).

14 Véase la disputa entre el Teniente Asesor Letrado de Coquimbo y el Teniente Gobernador de Huasco en la causa criminal contra José María Quevedo. ANIC, vol. 13, 26 de febrero de 1821, sin foja; o la comunicación del delegado de San Isidro de Vicuña, quien comunica al Intendente desconocer las atribuciones y el grado de extensión de las facultades del juez de letras de Coquimbo, señalando además que la Constitución no indica sus facultades. ANIC, vol. 14, San Isidro de Vicuña, 9 de agosto de 1824, sin foja, firma Santiago Iglesias.

15 Véase, por ejemplo, ANIC vol. 7, Vallenar, 20 de octubre de 1817, sin foja; vol. 3, 21 de enero de 1818, sin foja, firma Miguel Zañartu; vol. 13, 4 de noviembre de 1824, sin foja;; vol. 17, La Serena 14 de octubre de 1825, foja 355, firma Ramón Varela. 
en 1830 a las oficinas fiscales de la provincia, destaca que debió separar de sus cargos a los oficiales "que sin depacho del Supremo Gobierno se hallaban empleados en ella" (AMH, vol. 74, La Serena, 6 de septiembre de 1830, sin foja). Pero eso es a fines de la década estudiada y el gobierno conservador busca justamente centralizar la administración y establecer claras jerarquías verticales (Arias 2010).

Los vaivenes políticos tienes efectos indiscutibles en la administración local del territorio. Con la creación de las asambleas provinciales en 1823 y 1825, por ejemplo, se nombran nuevos funcionarios y este órgano representativo pasa a desempeñar labores administrativas que antes correspondían al Intendente y al poder ejecutivo central. Sin embargo, observamos que subyace una cierta estabilidad a los acontecimientos del día a día. Los motivos son variados: el tamaño reducido de la administración local, el que muchos funcionarios sean oriundos de la provincia o estén vinculados a las familias notables locales, y la circulación de los mismos entre las distintas instituciones del gobierno y órganos representativos.

La precariedad de la administración se manifiesta también en la dificultad de contar con sujetos aptos para ocupar los cargos públicos. Se señaló que uno de los motivos para nombrar militares en puestos administrativos era la necesidad de establecer aliados a la causa y a la persona del director supremo, pero también es cierto que no todos los individuos contaban con las habilidades necesarias para desempeñarse en las oficinas fiscales, en la administración, o como jueces de letras. En el ámbito judicial por ejemplo, en la provincia de Coquimbo se repite el nombre de Manuel Antonio González, quien se desempeña como asesor, juez de letras e Intendente de la proivincia. En su calidad de asesor presenta reiteradamente su renuncia, pero no le es aceptada pues no hay un letrado que pueda subrogarle. Por ello se le pide mantenerse en el cargo, "[...] es preciso que añada a los sacrificios que como buen ciudadano ha hecho en obsequios de la Patria, el de esperar mejor proporcion para que se le admita la renuncia que hace" (ANIC vol. 3, 24 de enero de 1818, sin foja, firma Miguel Zañartu).

Tras la victoria de Chacabuco, la mayor parte de los altos cargos administrativos realistas huye del conflicto y del acoso al que son sometidos por el nuevo gobierno, por lo que muchos puestos quedan vacantes. Pese a ello, una vez afianzada la independencia y cuando comienza a ejecutarse el proyecto de construcción estatal, se recurre al savoir faire de antiguos funcionarios coloniales, al de aquellos que se quedaron en el país y reconocieron al nuevo régimen, y que en algunos casos se incorporan a la nueva planta administrativa. 
Los patriotas heredan una organización administrativa que si bien desestructurada, sigue funcionando en la medida de lo posible, y cuya normativa y reglamentación se mantiene vigente. De forma paralela, sin embargo, se establecen nuevas formas de acceder a los cargos administrativos. Es por ello que las solicitudes de asensos y nombramientos utilizan un lenguaje ambiguo, que dependiendo de las circunstancias apelará a una u otra práctica, a las formas antiguas de acceso a un empleo o a las modernas.

Bajo el nuevo orden, el patriotismo no es el único requisito para acceder a un cargo público, la competencia necesaria para su ejercicio es también fundamental, tanto más cuanto uno de los tópicos del régimen es que este reconoce los méritos antes que el estatus, como habría sido el caso durante la colonia. Los decretos sobre asensos reiteran este punto, "Habiendo llegado a Chile el glorioso día en que solo se atiende la virtud al mérito para dispensar los premios". Estipulando que se prefiera a quienes cuentan con una formación adecuada al puesto que solicitan (Chile 1908: 229). Las vacantes son examinadas "prolijamente sobre los conocimientos del oficio", se investiga la conducta, aunque con privilegio de las aptitudes.

No obstante, la competencia necesaria para ejercer un cargo público está dada por una experticia que muchas veces los patriotas no tenían. En el caso del Departamento de Hacienda esto será un problema grave; son pocos los individuos con conocimientos amplios en materia de finanzas, hay más bien casos aislados, de quienes por desempeñarse en la administración o por dedicarse al comercio, tienen un conocimiento parcial del tema. Los nombramientos directos son una de las estrategias para ubicar a individuos fieles y que a su vez cuenten con las aptitudes necesarias. En Coquimbo se nombra así al administrador de alcabalas de la Intendencia de Coquimbo, Fernando de Urizar (AMH, vol. 2, Santiago, 27 de agosto de 1818, foja 105), y al administrador de alcabalas del partido de Huasco, Jerónimo Aguirre (AMH, vol. 29, sin foja, Santiago, 9 de diciembre 1818, sin foja).

En junio de 1820 se dicta un decreto con las disposiciones para el nombramiento de los empleados del Departamento de Hacienda, este dice: "Deseando elegir para los empleos personas de probidad y amor patrio, que reúnan al mérito adquirido los conocimientos necesarios al mas exacto desempeño de sus deberes" (Chile 1908: 262), se solicita a cada jefe de oficina que envíe al Ejecutivo una hoja de servicio de cada empleado arreglada a un modelo, debiendo reiterar esta operación con las variantes que hubiesen sufrido a principio de cada año (Chile 1908: 262). La hoja de servicio debe mencionar: nombre, lugar de nacimiento, edad, instrucción, aptitud y talento, aplicación, conducta, años de servicio en oficinas de Hacienda, en qué carrera o destino, y el total de años en servicio. También 
desde cuándo es adicto a la causa de la independencia de América, si se decidió a ella por actos públicos, si es o no ciudadano, y en qué comisiones se ha desempeñado. Pueden acompañarse recomendaciones del Intendente o Gobernador, además de la firma del jefe respectivo.

La información requerida muestra cuáles son los requisitos fundamentales que debe cumplir un funcionario, y muestra también el equilibrio que se busca establecer entre las competencias necesarias para el ejercicio del cargo, y las relaciones, vínculos y redes que configuran la administración. Pero este equilibrio es muy precario, como lo ilustra el siguiente caso.

En diciembre de 1822 el contador de la Aduana de Coquimbo, José Manuel Hernández, sufre "el ilegal despojo de su empleo" por el Intendente interino de la provincia Juan Martín Gallo. Ante su insistencia para recibir una explicación, el Cabildo le comunica que fue a petición de Marcos Gallo y de Gregorio Cordobés (ambos diputados de la Asamblea Provincial recién proclamada). A principios de marzo se le comunica que debe rendir cuentas a los nuevos ministros de la Aduana, sin explicarle las razones por las que se le separa del cargo "por medio de la sorpresa, sin figura de juicio alguna”.

Tras una larga lamentación el Contador apunta como culpable a Gregorio Cordobés. Señala como sabido de todo el vecindario que cuando se nombró al administrador de alcabalas de la provincia, Fernando Urizar, este advirtió los fraudes en la renta de la alcabala del viento y propuso su remate, pues pese a la vigilancia del contrabando "especialmente contra don Gregorio Cordoves" y al registro de su tienda, el administrador no había tenido éxito en la recuperación de los caudales. Cordobés fue uno de los individuos más empeñados en la subasta, aunque no lo consiguió para el primer bienio. En la segunda oportunidad este ofreció al antiguo ganador un monto a cambio de que no le hiciese oposición, y se adjudicó el remate. El resultado fue que Cordobés quedó al descubierto en alrededor de $\$ 5.000$, bajo la garantía de su hermano Gregorio.

Hé aqui uno de los poderosos motivos por que tan despechadamente se empleo el asambelista don Gregorio en la colocacion de su hermano, llegando su audacia al extremo de amenaza como que se hallaba a la frente de los cazadores y su hermano don Manuel Comandante de los Nacionales. Y hé aqui el modo de negociar mas facilmente la solucion de mas de seis mil pesos que deve don Antonio a su hermano don Gregorio y primo politico don Custodio de Amenabar (ANIC, vol. 
17, foja 312, firma José Manuel Hernández) ${ }^{16}$.

El Contador concluye señalando "que no es preciso un telescopio para descubrir el espitritu que anima a estos individuos", y solicita a la autoridad su reposición en el empleo (ANIC, vol. 17, foja 312, firma José Manuel Hernández).

El ejemplo citado da cuenta de los vínculos que existen entre la administración, en su rama de hacienda y ejecutivo, los comerciantes locales, los diputados provinciales y la jerarquía militar de la provincia; y cómo estos pueden primar por sobre el buen desempeńo del funcionario. Sin embargo, esta es una característica de la administración patrimonial que impera en la primera mitad del siglo XIX en las recientes repúblicas latinoamericanas (Garavaglia y Pro 2013). Lo que sucede en Coquimbo no es una excepción sino la regla.

\section{CONSIDERACIONES FINALES}

Tras la guerra civil de 1829 y la instauración de los conservadores en el poder, el gobierno encarga una visita fiscal a la provincia de Coquimbo. El Visitador se explaya sobre las virtudes de la provincia, desde una perspectiva geográfica, económica y demográfica, y señala la necesidad de levantar una estadística, "la primera urgencia de un pueblo que quiere constituirse y fijar sobre cimientos sólidos las vicisitudes de su existencia política" (AMH, vol. 74, La Serena, 21 de septiembre de 1830, s/foja).

El requerimiento del Visitador Fiscal destaca la falta de conocimientos que tiene el gobierno central del territorio nacional, desconocimiento no solo de su geografía, sino que de su población, producción económica, catastro de propiedades, comercio, etc. Pero esta visión contrasta con su mirada sobre orden administrativo, que parece conocer muy bien. En este ámbito, constata un estado de inercia en el que priman "costumbres inveteradas y rutinas perniciosas" que requieren no solo mejoras sino reformas radicales.

Las denuncias a los vínculos sociales y familiares que operan en la provincia, por ejemplo, revelan el ímpetu del nuevo gobierno por introducir reformas en pos de la eficiencia burocrática, pero muchos de estos esfuerzos

16 Custodio Amenábar había sido nombrado para la comisión de Secuestros (1817), junto a su primo político Antonio Cordobés (diputado en la Asamblea Provincial de 1822). En el año 1823 será elegido diputado suplente por Elqui en la Asamblea Provincial, y diputado suplente por Coquimbo en el Congreso nacional Constituyente de 1826. 
resultarán también en letra muerta. Por otra parte, el informe muestra que pese a la precariedad y a lo difuso que resulta para nosotros reconstruir el entramado de funcionarios, el gobierno sí lo conocía y comprendía las lógicas que guiaban sus prácticas; aunque las considerara perjudiciales al buen desempeño de la burocracia.

A lo largo de las páginas precedentes se vio que la década de 1820 es un momento complejo, tanto política como económicamente; y es en el marco de la omnipresencia de la guerra y de la situación de precariedad que la acompaña, que debe organizarse la administración pública. Una administración que en la provincia de Coquimbo es pequeña, y vinculada principalmente al gobierno local y al Departamento de Hacienda. Las cifras presentadas no dejan dudas sobre el objetivo de los primeros años de gobierno: ganar la guerra y afianzarse en el poder, y esto se refleja en la organización de la administración, en los recursos que se le destinan y en las medidas que implementan las autoridades.

La conformación de la administración provincial plantea también la disyuntiva entre la acomodación a la tradición y la innovación. Las lógicas heredadas, como el uso de vínculos y lealtades para acceder o conservar un puesto, siguen presentes, y las reformas, como lo apunta el Visitador Fiscal, encuentran fuertes resistencias.

Finalmente, las características analizadas muestran que el proceso de formación estatal tiene mucho de coyuntural, de inventivo, de improvisación y de pragmatismo. Las autoridades sorteaban los desafíos que se les presentaban con la mejor de las disposiciones, pero sin contar con los recursos materiales ni humanos necesarios. 


\section{REFERENCIAS}

Aracena, F. M. (1884). Apuntes de Viaje. La Industria del Cobre en las Provincias de Atacama y Coquimbo, los Grandes y Valiosos Depósitos Carboniferos de Lota y Coronel en la Provincia de Concepción. Santiago: DIBAM, Cámara Chilena de la Construcción, Pontificia Universidad Católica de Chile.

Arias, K. (2010). Revisión de las Estructuras Político-Administrativas Territoriales en el Chile del Siglo XIX. Revista Universum, 25 (1), 4459.

Barros Arana, D. (1889). Historia Jeneral de Chile. Tomo 10. Santiago: Rafael Jover Editor.

Bilot, P. (2012). "Las Causas por Torcida Administración De Justicia: Mirada Letrada hacia Prácticas Legas en Chile, 1824-1875. SudHistoria, 5, 99-123.

Carmagnani, M. (1963). El Salariado Minero en Chile Colonial. Su Desarrollo en una Sociedad provincial: el Norte Chico 1690-1800. Santiago: Editorial Universitaria.

. (1973). Les Mécanismes de la Vie Économique dans une société Coloniale, le Chili: 1680-1830. París: S.E.V.P.E.N.

Cavieres, E. (1993). La Serena en el Siglo XVIII. Las Dimensiones del Poder Local en una Sociedad Regional. Valparaíso: Ediciones Universitarias de Valparaíso, Universidad Católica de Valparaíso.

. (1998). Comercio Chileno y Comerciantes Ingleses 18201880. Un Ciclo de Historia Económica. Valparaíso: Universidad Católica de Valparaíso.

Cartes, A. (2014) “Un Gobierno de los Pueblos...”. Relaciones Provinciales en la Independencia de Chile. Valparaíso: Ediciones Universitarias de Valparaíso.

Chile (1818). Constitución de 1818.

. (1898). Boletín de las Leyes i Decretos del Gobierno, 18101814. Santiago: Imprenta Nacional, 1898. 
. (1908). Boletín de las Leyes y Decretos del Gobierno, 18191820. Santiago: Imprenta Nacional.

Dirección General de Contabilidad (1901). La Hacienda Pública de Chile desde la Independencia hasta 1900. Santiago: Imprenta Cervantes.

Domeyko, I. (1876). Ensayo sobre los Depósitos Metaliferos de Chile, con relación a su Jeología y configuración Esterior. Santiago: Imprenta Nacional.

Enríquez, L. (2016). Disputas Jurisdiccionales del Antiguo Régimen en el Chile Independiente: Patronato y Jurisdicción Regular. En Lupi, M. y Rolle, C. (Eds.), El Orbe Católico: Transformaciones, Continuidades, Tensiones y Formas de Convivencia entre Europa y América. Siglos IV -XIX. Santiago: RIL Editores.

Eyzaguirre, J. (1967). Historia de las Instituciones Politicas y Sociales de Chile. Santiago: Editorial Universitaria.

Garavaglia, J. C. y Pro, J. (2013). Latin American Bureaucracy and the State Building Process (1780-1860). New Castle upon Tyne: Cambridge University Press.

Godoy, M. (2016). La Ley es una Moneda en el desierto. Agentes Estatales, Empresarios Mineros y Conflictos de Intereses en la Periferia del Estado Nacional Chileno: Taltal 1850-1900. Estudios Atacameños. Arqueología y Antropología Surandinas, 52, 31-48.

Góngora, M. (1981). Ensayo Histórico sobre la Noción de Estado en Chile en los Siglos XIX y XX. Santiago: Ediciones La Ciudad.

Gribaudi, M. (2009). Les Savoirs des Relations: Liens et Racines Sociales d'une Administration dans la France du XIXe Siècle. Le Mouvement Social, 228, 9-38.

Heise, J. (1978). Años de Formación y Aprendizaje Político, 1810-1833. Santiago: Editorial Universitaria.

Hurtado, C. (1966). Concentración de Población y desarrollo Económico. El Caso Chileno. Santiago: Universidad de Chile.

Imízcoz. J. M. (1998). Communauté, Réseau Social, Elites. L’armature Sociale de l'Ancien Régime. En Castellano, J. L. y Dedieu, J. P. (Eds.), 
Réseaux, Familles et Pouvoir dans le Monde Ibérique à la Fin de l'Ancien Régime. Paris: CNRS Editions.

Jocelyn-Holt, A. (1992). La Independencia de Chile. Tradición, Modernización y Mito. Madrid: Mapfre.

. (1997). El Peso de la Noche: Nuestra Frágil Fortaleza Histórica. Buenos Aires: Ariel.

Letelier, V. (1886). Sesiones de los Cuerpos Lejislativos de la República de Chile 1811 a 1845. vol. II. Santiago: Imprenta Cervantes.

López Taverne, E. (2011). La Hacienda Pública en Chile 1824-1860. Una Aproximación a la Realidad Provincial. En GARAVAGLIA, J. C. y Contente, C. (Ed.), Configuraciones estatales, regiones y sociedades locales. América Latina, Siglos XIX-XX. Barcelona: Ediciones Bellaterra.

. (2014). El Proceso de Construcción Estatal en Chile. Hacienda Pública y Burocracia (1817-1860). Santiago: Centro de Investigaciones Diego Barros Arana/DIBAM.

Ministerio de Hacienda (1824). Memoria que el Ministro Secretario de Hacienda Presenta al Congreso de la República de Chile, diciembre de 1824, Santiago: Imprenta Nacional.

Oficina de Estadísticas (1861). Anuario Estadístico de la República de Chile, tomo III. Santiago: Imprenta Nacional.

O’Donnell, G. (2004). Acerca del Estado en América Latina Contemporánea. Diez Tesis para una Discusión. En Programa de las Naciones Unidas para el Desarrollo (PNUD) (Ed.), La Democracia en América Latina. Hacia una Democracia de Ciudadanas y Ciudadanos. Buenos Aires: PNUD.

Ortega, L. (2005). Chile en la Ruta al Capitalismo. Cambio, Euforia y Depresión 1850-1880. Santiago: DIBAM, Ediciones LOM, Centro de investigaciones Diego Barros Arana.

Ossa, J. L. (2014). Armies, Politics and Revolution. Chile, 1808-1826. Liverpool: Liverpool University Press.

Pérez Rosales, V. (1859). Ensayo sobre Chile. Santiago: Imprenta El Ferrocarril. 
Pietschmann, H. (1998). Corrupción en las Indias Españolas: Revisión de un Debate en la Historiografía sobre Hispanoamérica Colonial. En González M., Pietschmann, H. y Comín, F. (Coords.), Instituciones y Corrupción en la Historia. Valladolid: Universidad de Valladolid, Instituto Universitario de Historia de Simancas.

Pinto, J. (2011). ¿La Tendencia de la Masa al Reposo? El Régimen Portaliano Enfrenta al Mundo Plebeyo, 1830-1851. Historia, 44 (2), 401-442.

Pinto, J. y Ortega, L. (1990). Expansión Minera y Desarrollo Industrial: Un Caso de Crecimiento Asociado (Chile 1850-1914). Santiago: Departamento de Historia, Universidad de Santiago de Chile.

Pinto, J. y Valdivia, V. (2009). ¿Chilenos Todos? La Construcción Social de la Nación (1810-1840). Santiago: Ediciones LOM.

Pinto Rodríguez, J. (2003). La Formación del Estado y la Nación y el Pueblo Mapuche. De la Inclusión a la Exclusión. Santiago: DIBAM, Centro de Investigaciones Diego Barros Arana.

Pro. J. (2013). Considering the State from the Perspective of Bureaucracy: Lessons from the Latin American Sattelzeit. En Garavaglia, J. C. y Pro Ruiz. J. (Eds.), Latin American Bureaucracy and the State Building Process (1780-1860). Newcastel upon Tyne: Cambridge Scholars Publishing.

Rudolph, L. y Hoeber, S. (1984). Autoridad y Poder en la Administración Burocrática y Patrimonial. Una Interpretación Revisionista de las Ideas de Weber sobre la Burocracia. En Ozlak, O. (comp.), Teoría de la Burocracia Estatal: Enfoques Críticos. Buenos Aires: Editorial Paidós.

Salazar, G. (2009). Mercaderes, Empresarios y Capitalistas (Chile, siglo XIX). Santiago: Editorial Sudamericana.

Salazar, G. y Pinto, J. (1999). Historia contemporánea de Chile. Volumen 1. Santiago: Ediciones LOM.

\section{Archivos consultados}

Archivo Nacional de Chile, Fondo Intendencia de Coquimbo (ANIC), vols. 3, 6, 7, 13, 14, 17, 25. 
Archivo Nacional de Chile, Fondo Ministerio de Hacienda (AMH), vols. $2,3,29,74,113$.

Archivo Nacional de Chile, Fondo Ministerio del Interior (AMI), vols. 9, 46.

Recibido: 16-11-2016

Aceptación de la versión final: 27-12-2016 